Apuntes Universitarios, 2020: 10(4), octubre-diciembre

ISSN: 2304-0335 DOI:https://doi.org/10.17162/au.v10i4.508

\title{
Aspectos metodológicos de la evaluación de la eficiencia de la política social regional en la superación de la orfandad social
}

\author{
Methodological aspects of assessing the efficiency of regional social policy in \\ overcoming of social orphanhood
}

\author{
Sergey V. Babakaev ${ }^{1}$, Olga S. Kulyamina², Evgeniya M. Bronnikova ${ }^{3}$, \\ Marina V. Vinogradova ${ }^{4} \&$ Valentina P. Leonova ${ }^{5}$ \\ Russian State Social University, Moscow, Russia ${ }^{12345}$ \\ Orcid ID: https://orcid.org/0000-0001-9332-9347 1 \\ Orcid ID: https://orcid.org/0000-0001-7715-55512 \\ Orcid ID: https://orcid.org/0000-0002-5409-97263 \\ Orcid ID: https://orcid.org/0000-0002-5051-9404 \\ Orcid ID: https://orcid.org/0000-0001-9332-9347
}

Recibido: 13 de febrero de 2020

Aceptado: 17 de julio de 2020

\begin{abstract}
Resumen
Entre las cuestiones metodológicas de estudiar el problema de la orfandad social, un lugar importante está ocupado por la búsqueda de marcadores efectivos para evaluar la dinámica, por un lado, y la efectividad de la política social para superar la orfandad social, por el otro. Ese intento de evaluar sistemáticamente la escala y la gravedad del fenómeno, así como los factores clave que determinan su dinámica. Sin embargo, estos enfoques no nos permiten identificar la conexión entre el trabajo social y la dinámica de mejorar la situación con la orfandad social en la región. El estudio presentado propone un nuevo modelo para evaluar la dinámica de la orfandad social. Su diferencia con otros enfoques metodológicos es que el énfasis principal está en evaluar la orientación del complejo de cambios en los procesos de identificación, colocación de huérfanos y cancelación de decisiones sobre su transferencia a las familias. Este modelo nos permite evaluar el papel de la política social en la superación de la orfandad social. En este modelo, desarrollamos métodos de autor para clasificar las regiones de Rusia por la dinámica de los indicadores integrados en el índice de "auspiciosidad" de los cambios en la orfandad social. Además, el autor presenta un modelo que evalúa la situación en la región desde el punto de vista del "índice de eficiencia del apoyo social" para superar la orfandad social. Los modelos utilizados para evaluar la dinámica de la orfandad social se han probado como una herramienta para identificar marcadores clave de la eficiencia de la política social.
\end{abstract}

Palabras clave: investigación metodológica, orfandad social, política social, metodología de evaluación, apoyo social. 


\section{Abstract}

Among the methodological issues of studying the problem of social orphanhood, an important place is occupied by the search for effective markers for assessing dynamics on the one hand, and the effectiveness of social policy in overcoming social orphanhood on the other. That attempt to systematically evaluate the scale and severity of the phenomenon, as well as the key factors that determine its dynamics. However, these approaches do not allow us to identify the connection between social work and the dynamics of improving the situation with social orphanhood in the region. The presented study proposes a new model for assessing the dynamics of social orphanhood. Its difference from other methodological approaches is that the main emphasis is on assessing the orientation of the complex of shifts in the processes of identifying, placement of orphans and canceling decisions on their transfer to families. This model allows us to assess the role of social policy in overcoming social orphanhood. In this model, we developed authoring methods for ranking the regions of Russia by the dynamics of indicators integrated into the "auspiciousness" index of changes in the social orphanhood. Also, the author presents a model that assesses the situation in the region from the point of view of the "social support efficiency index" to overcome the social orphanhood. The models used to assess the dynamics of social orphanhood have been tested as a tool for identifying key markers of the efficiency of social policy.

Keywords: methodological research, social orphanhood, social policy, evaluation methodology, social support.

\section{Introduction}

The search of the ways of the valid evaluation of the social work efficiency to overcome social orphanhood in the regions are relevant methodological problem. The search for adequate methods and tools for measuring two key processes and trends depends on its decision. First, the dynamics of the development of social orphanhood (Orphanhood in the regions of Russia, 2018). Secondly, the determination of the conformity of the social policy pursued in the region with the scope and content of the problem of social orphanhood (Reznichenko et al, 2018). Thus, the methodological issues of solving this problem includes two main aspects. On the one hand, the identification of the dynamics of social orphanhood, on the other hand, the search for the main markers of the focus of social policy (Gudarenko, 2014). Currently, there are a number of approaches determining the scale and dynamics of social orphanhood, within which a system of social indicators has developed the aspects of a negative social phenomenon (Sushko, 2017). However, the authors of the approaches acknowledge the limitations in the use of ratings based on aggregate indicators of social orphanhood (Orphanhood in the regions of Russia, 2019).

The first limitation is that the ratings only allow us to demonstrate the scale of the problem of social orphanhood in the region and do not allow us to assess the effectiveness of the regional state policy to overcome social orphanhood. The second limitation is that the rating of a region reflects only its place in comparison with other regions in terms of the scale of manifestation of social orphanhood. Even if it's indicators improves, it may still fall back due to the fact that other regions have had higher average in overcoming of the social orphanhood. The third limitation is the use of the official state statistics. The official statistics, as a result of the interagency approach, are characterized by some inconsistency between the categories and 
different interpretations in the use of indicators and methods for measuring them. Our approach, based on state statistics, is aimed at overcoming the first two restrictions. This was achieved in three ways. First, give a rating of the regions based on the shifts that have occurred in terms of improving the situation. Secondly, to develop a new regional index of the effectiveness of social policy in terms of overcoming social orphanhood. Thirdly, by means of the opportunity to conduct a comparative analysis of the index values reflecting favorable shifts in the situation of social orphanhood and the index fixing the effectiveness of social policy in terms of creating favorable conditions for overcoming social orphanhood.

The novelty of the study is in implementation the approach to the study of the problem of social orphanhood in a new way, the regions are classified and ranked according to the "auspiciousness" index of the development in situation of social orphanhood (Kvon et al, 2017; Zaitseva et al., 2018). Basically, most studies examine the situation of orphanhood from with the severity of the problem. The novelty of the approach is in the new methodology for assessing the combination of available statistical data that reflects the processes and phenomena, by different aggregation of different indicators and empirical referents.

The new approach to aggregation of various indicators of social orphanhood dynamics is based on the desire to isolate the aspect of the research area that has not yet been studied. First of all, to determine the place and role of social policy in the region. Social policy is considered as a key factor in the localization of the problem of social orphanhood, which determines the dynamics of the development of this process. Achieving this goal of the study will allow us to identify hypothetical growth points and drivers of social development that determine the positive direction of shifts in solving the social orphanhood's problems.

The relevance of the study is the need for a tool to assess the development of the situation at an early stage of the growth of negative tendencies. As such a tool, it is proposed to use the "auspiciousness" index of social orphanhood dynamics of indicators with a subsequent assessment of the situation by the index of the effectiveness of social policy. Therefore, the practical significance of the approach lies in the ability to recognize the problem of social orphanage at an early stage.

\section{Methods}

The theoretical and methodological basis of a new approach to assessing the effectiveness of social policy in overcoming of social orphanhood is the concept of anomie. It explains the phenomenon of social orphanhood by the dynamics of the modern life, which contributes to the breakdown of social connections and institutions, including family relations (Roche, 2019; Miranda, Tadros \& Molla, 2020). As a result of the growth of anomie in society, social orphanhood increases (Vasilieva \& Frolova, 2019; Maribel \& Roger, 2018; Lukina \& Trifonova, 2018). The reasons for the appearance of social orphanhood, as well as the position 
of orphans in society, if we consider them as a part of theory of anomie, require an integrated approach to explanation and solution (Eremina, 2014; Lukina \& Trifonova, 2018; Manerova \& Markina, 2018; Cooley et al., 2020).

Therefore, the basis of the methodological requirements for the study of this phenomenon is a holistic systematic approach to identifying ways to localize social orphanhood with a set of measures related to a social policy. In this theoretical and methodological context, public policy aimed at overcoming social orphanhood, in our opinion, should be considered in a wide social context (Istomina, 2018; Tazik, et al 2019). It is necessary to conduct an unified social policy designed to minimize the consequences of the anomicity of modern society. Currently, the approach to solve the problem of social orphanhood is narrowed. The main research attention does not go beyond the scope of direct measures to identify, arrange social orphans and provide social support to poor families and people in difficult situations. At the same time, other activities of social policy having a direct impact on the development of the situation with social orphanhood in the region, often not enough researched (Manerova \& Markina, 2018; Palibina, 2018; Chursina \& Rodina, 2018).

During the construction of a new model for assessing the dynamics of the situation with social orphanhood, the following main research tasks were solved:

- the main indicators of the dynamics of the processes in three blocks of problems of social orphanhood are fixed (the emergence of orphans; the placement of orphans; the return of orphans), fixing the positive (favorable) vector of development of the situation with social orphanhood;

- $\quad$ the Russian regions were classified and ranked according to indicators reflecting the dynamics of the development of the social orphanhood with their further stratification by clusters (groups) depending on the identified trends and the general vector of its development;

- $\quad 11$ regions representing the main clusters (groups) of the development of the social orphanhood were selected for a more detailed analysis and testing of the new approach. Further, a comparative analysis of the influence of factors on the dynamics of development based on a desk study was carried out.

- $\quad$ points of growth and drivers of social development are determined on the basis of verification and selection of scientific hypotheses that express connections between different characteristics of the object and the subject of research.

Thereupon, the object of the study is the process of developing a new method for determining the dynamics of changes in the situation in Russian regions with social orphanhood (the time period 2015-2018), aimed at identifying the main shifts in the development of the 
situation. The focus of the discussion of this method is aimed at the possibility of its application and determining the validity of the results.

The subject of the research is the sequence of constructing a research model for classifying regions and identifying the main conditions and factors affecting the processes under study, as well as possible growth points and drivers of social development, contributing to an improvement of the social orphanhood.

The construction of new models, the assessment of auspiciousness of shifts with social orphanhood, and the effectiveness of social policy are based on typical indicators used in statistical reporting forms (Russian Regions. Socio-economic indicators , 2017). Data sources are the Federal state statistics service (2019) of the Russian Federation (Diagram Analysis the state of the protection of children's rights in the region) with the exception of demographic indicators (the proportion of children in each region); statistical reporting form No. 103-RIK, responsible for collecting information: the Ministry of Education and Science of the Russian Federation, and the Ministry of Education of the Russian Federation since 2018 (Summary reports on the form of federal statistical observation No. 103-RIK 2018 for Russia and the subjects of the Russian Federation, 2019).

\section{Results}

\section{Approaches, general concept and the main hypotheses of the study}

The main criteria and indicators of the "tension" of the situation are variables reflecting different aspects of the situation with orphanhood, including:

- children in need of a family arrangement. The indicators of the total number of orphans and children left without parental care who are not brought up in the family (blood, foster care, adoption) are recorded in the "children's data bank";

- the placement of children in families. This indicator reflects the proportion of children who are transferred to families (returning to blood parents, taken under guardianship or adopted) in the same year in which they were left without parental care;

- cancellation of family transfer decisions. This indicator shows the number of children whom decisions on adoption or guardianship are canceled for in the reporting year;

- return of children to blood families. This indicator shows the number of cases related to the elimination of the reasons for restriction or deprivation of parental rights. 
To assess the severity of the situation with social orphans, the reporting form No. 103 RIK of the Ministry of Education of the Russian Federation is used (Summary reports on the form of federal statistical observation No. 103-RIK 2018 for Russia and the subjects of the Russian Federation, 2019; Dehdar, et al 2019).

The importance of this approach is in an objective vision of the scale of social orphanhood in the country and in each federal region based on the construction of aggregated indixes by a set of indicators. It allows to rank regions according to the severity and scale of manifestations of social orphanhood, to evaluate the dynamics of indicators. However, this approach has several limitations. In particular, it does not allow to capture the positive systemic shifts that occur in the development of the situation, to identify the turning points (bifurcation points) of its improvement in order to detect the main drivers of social development related to the localization of this problem. Therefore, the concept of the study is based on the classification and ranking of regions by the quality of systemic changes in the development of the situation, which allows us to evaluate the favorability of changes.

The main hypothesis of the study is that regions in a favorable zone of shifts in social orphanhood, in comparison with relatively unfavorable regions, will be characterized by a higher social support efficiency index. Confirmation of this hypothesis may mean the existence of a direct link between the social policy in the region and shifts in the situation of social orphanhood. The following hypotheses were put forward:

- $\quad$ in the underfunding of social policy regions, where social support for families, mothers and children is low, there is a high probability that the region will be in an unfavorable zone of changes in the situation of social orphanhood;

- $\quad$ in the regions where families in difficult life situations do not receive proper social support, the risks of negative dynamics of social abandonment will be higher;

- the aggravation of the problem with orphanhood will be observed in the regions where social support for motherhood and childhood is poorly conducted, insufficient assistance to the protection of children rights is provided;

- the living arrangements for orphans, the problem of the return and the appearance of orphans will be more pronounced in the regions where the social support policy is less implemented. This concerns governmental support for parents and family; legislative support of the rights of child; ensuring governmental standards for key indicators children's quality of life; support for the activities of youth and children's organizations by the state.

Conducting of methodological study and testing the hypotheses is based on the study of the practical implementation of regional social policies aimed at supporting of motherhood and 
childhood, protecting the rights of the child based on the social support efficiency index.

\section{A way to assess the dynamics and identify turning points in the development of the situation with social orphanhood to calculate the "auspiciousness" index}

The methodology for assessing the dynamics of the situation with social orphanhood includes a sequence of operations implemented in five main stages.

At the first stage, a list of indicators of the main aspects of social orphanhood dynamics is formed. The dynamics indicators of the identification of orphans "I", the placement of identified orphan " $\mathrm{P}$ ", and the cancellation of transferring a child to a family decisions " $\mathrm{C}$ " is calculated for Russian Federation and its regions from the following basis:

- $\quad$ "I" - the percentage of children without parental care identified during the year in the total number of children living in the region (0-17 years old);

- $\quad$ "P" - the percentage of the children placed in families, including returned to parents, in the total number of identified children left without parental care;

- $\quad$ "C" - the percentage of canceled decisions of transfer a child to a family, in the total number of the placed children.

At the second stage, these indicators are transformed into points depending on the favorable (positive) or unfavorable (negative) direction of development of the situation with the dynamics of this indicator. A point value of + (plus) one point get indicators of positive dynamics of the situation. A point value - (minus) one point get indicators negative dynamics of the situation. The following scoring occurs depending on trends:

- dynamics of indicators "I " and "C" has a negative value for the observed period (decrease) +1 point; increase -1 point;

- $\quad$ dynamics of indicator "P" has a negative value for the observed period (decrease) 1 point; increase +1 point;

At the third stage, there is a further transformation of the obtained points with the quantitative dynamics of changes in each indicator. The quantitative values of the dynamics of the sign (changes in percentages/100) are added to the score with a positive or negative pole. The introduction of correction factor makes it possible not only to classify the changes, but to determine the "weight" of changes for the period. This makes it possible to measure the qualitative characteristics of the dynamics to distribute the regions according to the main clusters and to rank them depending on the quantitative parameters of the changes. To eliminate random fluctuations (a strong dispersion of the trait) and to equalize the values, a maximum 
oscillation threshold is set $(>100 \%)$. Therefore, the maximum fluctuation in the values of each indicator is located in a given continuum.

At the fourth stage, on the basis of weighing the values of the indicators, their normalization and leveling of the dynamic series (freeing from random deviations), they are further transformed by aggregating three indicators into the "auspiciousness" index. This index reflects the configurations of the process of improving the situation with orphanhood and the place of the region on the scale of index, which is in a continuum of values from +1 (maximum of a favorable development) to -1 (maximum of unfavorable development). The value "0" represents a turning point (bifurcation) trend. "Auspiciousness" index= "I" (summary score) + "P" (summary score) + "C" (summary score)/maximum total value of indicators.

At the fifth stage, the regions of the Russian Federation are distributed among four clusters: "green", "yellow", "orange", "red". Clusters reflect the situation of social orphanhood in terms of its systemic shifts in the identification of orphans "I", the placement of identified orphans "P", and the cancellation of transferring a child to a family decisions "C".

The regions in the "green" cluster (the most favorable changes), are characterized by the decrease of the indicator "I"; the increase of the indicator "P"; the decrease of indicator " $\mathrm{C}$ " in a period.

The regions in the "yellow" cluster (two indicators are favorable, one is unfavorable), characterized by the decrease of the indicator "I"; the increase or decrease of the indicator "P"; the decrease or increase of indicator " $C$ " in a period.

The regions in the "orange" cluster (one indicator is favorable, two are unfavorable), characterized by the decrease of the indicator "I"; decrease of the indicator "P"; the increase of indicator " $\mathrm{C}$ " in a period.

The regions in the "red" cluster (three indicators are unfavorable), characterized by the increase of the indicator "I"; decrease of the indicator "P"; the increase of indicator " $C$ " in a period.

After the classification of regions to the different clusters, a rating is based on distribution according to the "auspiciousness" index of the situation development. Further, in dependence on the values of the "auspiciousness" index, regions are ranked by the order of higher to the lower values. The highest value rating is in the regions of the "green" cluster, the lowest is in the "red" cluster.

\section{A method of constructing a "Social Support Efficiency Index" and the procedure for adding indicators for assessing the effectiveness of social policy}

The effectiveness of social policy is recorded by support of families and people in difficult situations. To assess the effectiveness of social support, we developed an aggregated index that allows us to build an integrated rating of the regions. This index is formed on the 
basis of aggregation of a number of statistical indicators presented in the summary information about protection of the children rights in the region for 2018 (Summary reports on the form of federal statistical observation No. 103-RIK 2018 for Russia and the subjects of the Russian Federation, 2019).

These indicators (variables and characteristics) were combined into 3 groups: P1 indicators of "favorable social effects"; P2 - indicators of "adverse social shifts"; P3 - indicators of "social support". Indicators of the assessment are calculated as the dynamics for the 3 years, the assessment was carried out by the sign (growth or decrease).

The social support efficiency index is a total score for indicators based on their weight, transformed by recalculating the points received from their maximum possible value into the efficiency scale with a continuum of values from 0 (absolutely ineffective) to 1 (most effective).

\section{Table 1}

The main indicators for assessing the effectiveness of social policy for the period 2016-2018

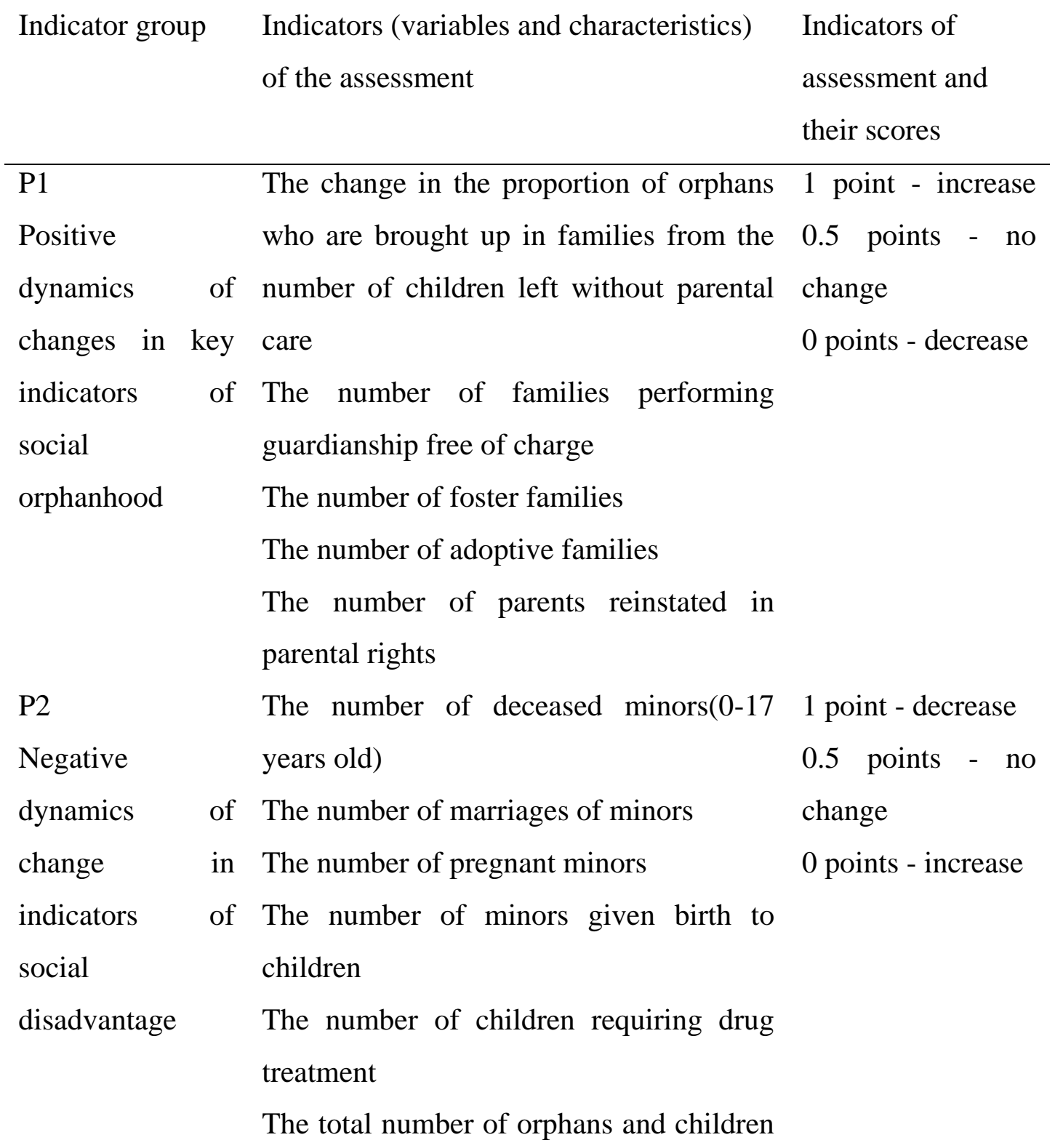




$\begin{array}{lll}\text { Indicator group } & \begin{array}{l}\text { Indicators (variables and characteristics) } \\ \text { of the assessment }\end{array} & \begin{array}{l}\text { Indicators of } \\ \text { assessment and } \\ \end{array} \\ & \text { their scores }\end{array}$

left without parental care

The number of foster parents with whom contracts were terminated prematurely by the initiative of the guardianship authority because of unfavorable conditions for the maintenance and education of children in the foster family The number of parents deprived of parental rights

The number of parents limited in parental rights

The number of disabled children

The proportion of orphans left without parental care from the number of children with disabilities

P3

Positive

dynamics

changes

indicators of state and non-state resource

provision social policy
The total number of preschool institutions The number of private preschool of institutions

in The number of children in foster families eligible for child support

The proportion receiving alimony from the number of eligible (of those who have the of right to receive it)

Introduction to the generalized indicator of a wide range of variables reflecting negative shifts in the situation with the protection of children's rights allows us to monitor indirect indicators of the low effectiveness of social support for the family, childhood, and motherhood, based on the negative dynamics of these social processes.

\section{General algorithm for testing tools and hypothesis}

Step 1 - We calculate the value of indicators of the "auspiciousness" index based on the methodology for assessing the situation of social orphanhood. We make a summary table of distributions for the period. 
Step 2 - We classify and group all the regions of the Russian Federation according to the "auspiciousness" index, compile their rating, and enter them in the general distribution matrix.

Step 3 - We select from each cluster (groups of regions of a certain color that characterize the situation with orphanhood) 2-3 regions to conduct a desk study of the main factors and conditions that determine the development of the situation (favorable and unfavorable trends and shifts).

Step 4 - We calculate the social support efficiency index based on the form of the regional reporting of the Ministry of Education of the Russian Federation (The analysis scheme of the state of protection of children's rights in the region, 2019) for those regions that are included in the system analysis group.

Step 5 - We carry out a comparative analysis of the selected regions in different clusters according to the "auspiciousness" index according to the social support efficiency index in the region to identify the connection between them.

Step 6 - We collect statistical information to evaluate:

- the severity of the problem of social orphanhood in each region of the Russian Federation selected for analysis (Orphanhood in the regions of Russia, 2019).

- the socio-economy position of the regions (Rating of the socio-economic situation of the regions, 2018; Rating agency "RIA Rating” of the media group MIA "Russia Today", 2019);

- $\quad$ the place of the region in 2017 according to the main socio-economic indicators (Regions of Russia, 2017)

Step 7 - We enter the additional information showing the ratings of the extent of orphanhood, socio-economic status, the place of the region according to the main indicators of socio-economic development in the database. This will allow us to represent the parameters for a comparative analysis and search for the connection between indicators that reflect the influence of various socio-economic factors.

Step 8 - We conduct a comparative analysis of selected regions representing different groups according to the "auspiciousness" index of changes in the social orphanhood according to ratings that reflect the system and structural aspects of the socio-economic situation. These ratings reflect the following aspects: the scale of orphanhood, the integrated rating (scale of the economy; economic efficiency; budget sphere; social sphere; level of economic and social development in the region).

Step 9 - We collect information about the social policy in the region. Particular attention is paid for information, which includes changes in the regulatory framework, contributing to the removal of the barriers in the development of the social sector, public-private partnership. Also the information about measures of stimulation of the social sphere, attracting investment and development in the social sphere is very important. The regional programs and plans for 
the development of the social sphere, the reports about implementation of social policies are important objects for the search and selection of information. Concepts (strategies) for social development of the region and programs that express the main models of social policy are of interest for analysis.

Step 10 - We analyze the information that displays various aspects of social policy and social development of the region. The analysis is based on the use of different formalized and unformalized methods of desk research. They allow to perform multi-factor research of the object. The study is carried out using a combination of analytical methods with the analysis of direct and indirect data on the object (research and analysis of factors affecting the object of study, both within its segment and going far beyond the segment, industry, region).

\section{Testing results of a new methodological approach}

In order to test the methodological approach, a comparative analysis of the selected regions, representing different clusters by the "auspiciousness" index of shifts in the social orphanhood by the social support efficiency index in the region, in order to identify possible connections between them was presented (table 2).

\section{Table 2}

Connection between the clusters of "auspiciousness" of changes in the social orphanhood and the social support efficiency index

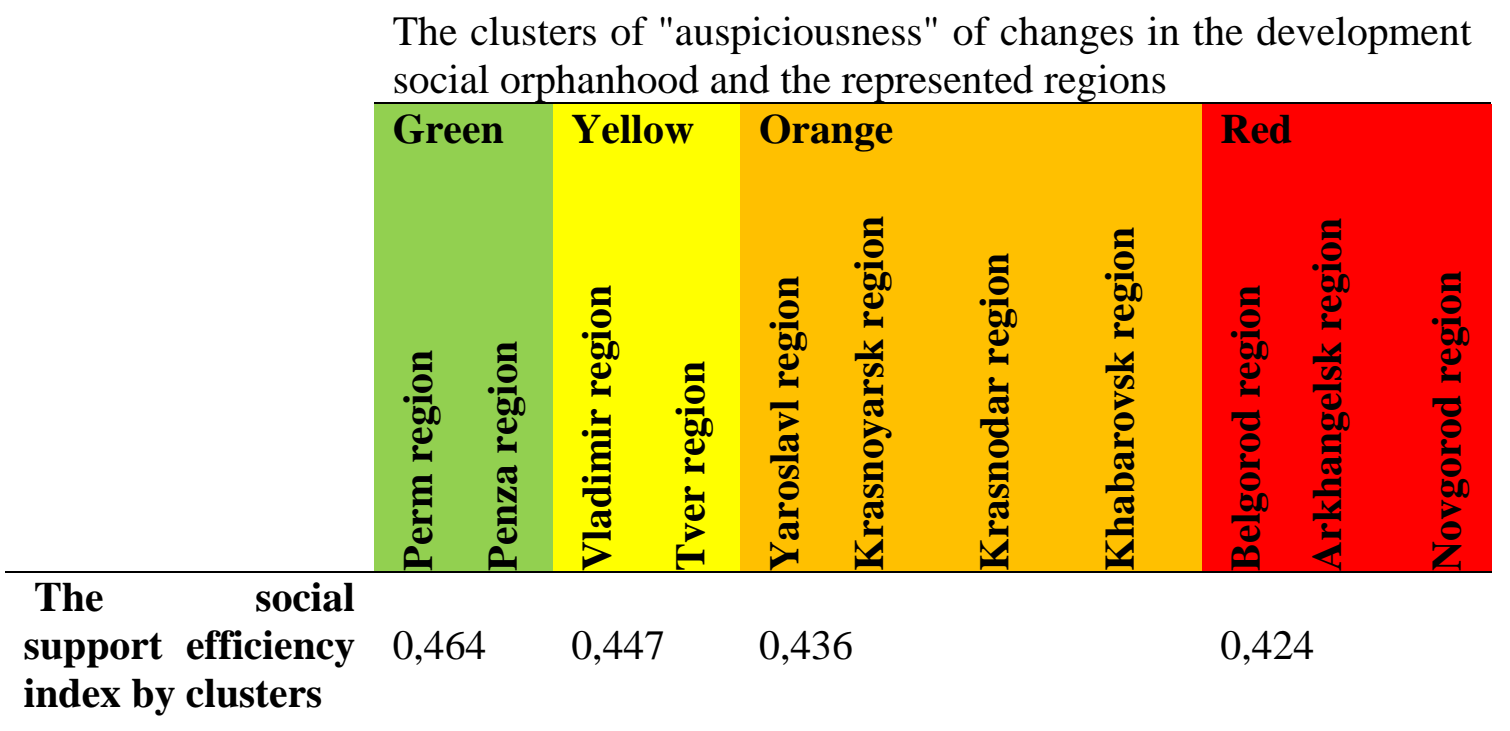

There is a slight inverse connection between the average values of the social support efficiency index in these clusters and the strengthening of the unsuccessful situation with social orphans at the level of regional clusters. Of course, it should be noted that the difference in the values of the index is insignificant, but it goes beyond the measurement error. Thus, in our scientific experiment, the tendency of dependence of the favorable development indices on the situation with social orphanhood and the effectiveness of social support is clearly visible. This 
trend may indicate the presence of some direct correlation between the effectiveness of social support for families and people in difficult life situations, on the one hand, and the decrease in the dynamics of the unfavorable development of the situation with social orphanhood on the other hand. And the methodological tools allow us to record the connection between improving the situation in the regions and the growth of the effectiveness of the social policy.

\section{Discussion}

The proposed method for assessing the favorable development of the social orphanhood allows, in our opinion, to identify both positive and negative shifts in the dynamics of the key factors and indicators that determine this process at an early stage with a fairly high degree of validity. Other advantages of this method include not only the possibility of using it to rank the regions according to the "auspiciousness" index but also to evaluate the impact of social support measures on the effectiveness of the regional social policy. To realize this opportunity, an additional social support efficiency index is introduced (social support for families and people in difficult life circumstances). These results are consistent with researches of Reznichenko et al (2018), Kvon et al (2017) and Zaitseva et al (2018). Reznichenko et al, 2018 pointed to the conformity of the social policy based on the region and considered it necessary. These results are also consistent with the concept of auspiciousness in researchs of Kvon et al (2017) and Zaitseva et al (2018), which has been considered in the ranking of social orphanhood.

Our scientific experiment revealed the connection between these indexes. From the point of view of the research methodology, the connection confirms the rather high validity of the proposed indicators and methods of aggregation of indexes. A serious limitation of the method is that it does not allow us to fix the extent of manifestation in each region of the social orphanhood problem on the one hand. On the other hand, methods for detecting the extent of orphanhood are well developed and widely used in practice.

In sum, the application of our method is aimed at finding turning points in the development of the situation in order to identify the main causes. Therefore, the use of our method should be supplemented by old methods for assessing the problems of social orphanhood in terms of the extent of its prevalence in the region.

\section{Conclusion}

The methodological approach for assessing the effectiveness of social policy for overcoming of social orphanhood has been tested in a limited number of regions representing the main clusters. These were formed on the basis of using the classification according to the "auspiciousness" index of the development of the situation with social orphanhood The use of this index allowed us to classify all regions not only by groups (clusters) representing a continuum of favorable shifts in the problem of social orphanhood, but also to rank them by 
regions. This classification, which allows to find turning points in the development of the situation with social orphans, opens up new opportunities in the search and determination of drivers and barriers for overcoming the negative phenomenon, taking into account the policy of social support in the regions.

This method makes it possible to conduct a comparative analysis of regions representing different groups according to the "auspiciousness" index of shifts in the situation with social orphanhood by ratings that reflect the system and structural aspects of development and the state of the socio-economic situation.

Additional collection of information on social policy in the region will allow to expand the possibilities of using the method of evaluating the effectiveness of social policy. Information that reflects changes in the legal framework helps to remove barriers in the development of the social sector and the development of public-private partnerships for social support of families is of particular value. The information about stimulating measures for the development of the social sphere and attract investment in the development of the social sphere is also of key importance. The regional programs and plans for the development of the social sphere, reports on the implementation are important objects of additional analysis within the proposed typology of regions. They offer considerable opportunities for removing barriers of increasing the effectiveness of social support for families.

Therefore, it is planned to supplement this method of assessing the effectiveness of social policies to overcome social orphanhood by developing a specific number of common contours of regional strategies in choosing the desired measures depending on a particular and contextual scenario.

\section{References}

Chursina, V. N. \& Rodina, A.A. (2018). Social orphanhood: causes and ways to overcome. New approaches and methods in sociology and social work Materials of the international scientific-practical conference, pp. 158-165.

Cooley, M.E., Womack, B., Rush, J. \& Slinskey, K. (2020). Adverse childhood experiences among foster parents: Prevalence and association with resilience, coping, satisfaction as a foster parent, and intent to continue fostering. Children and Youth Services Review, 66, 109-116.

Dehdar, M., Sayegani, L., Arbab, E., Arzhandeh, M., Roshanray, M., Raeisi, A., \& Kuhi, L. (2019). Role of schools in educating the active citizen. Journal of Social Sciences and Humanities Research, 7(02), 31-36.

Eremina, Y. S. (2014). The social aspect of the study of the problem of social orphanhood. Modern science: actual problems and solutions, 10, 134-138. 
Federal State Statistics Service. (2019). Regions of Russia. Socio-Economic Indicators 2018. URL: http://www.gks.ru/bgd/regl/b18_14p/Main.htm (accessed 10.09.2019).

Gudarenko, P.V. (2014). International experience in the application of social technologies for the early prevention of social abandonment. Scientific notes of the Russian State Social University, 3(125), 72-80.

Istomina, E. A. (2018). Compensation of the social risk of orphanhood: municipal level of social support. Municipality: economics and management, 4(25), 103-108.

Kvon, G. M., Lushchik, I. V., Karpenko, M. A., Zaitseva, N. A., Kulkov, A. A., Galushkin, A. A. \& Yakupova, N. M. (2017). Regional Investment Policy: Analysis and Assessment of the Investment Environment State. Eurasian Journal of Analytical Chemistry, 12(5b), 835-853.

Lukina, A.O. \& Trifonova, V.I. (2018). Social orphanhood as a phenomenon of modern society. Academy of professional education, 12, 46-51.

Manerova, O. A. \& Markina, A. Y. (2018). The current state of social orphanhood in Russia: factors and conditions for its formation. Diary of the Kazan Medical School, 3(21), 153158.

Maribel, S. P. \& Roger, D. S. (2018). Structural Changes in the Current Family. Reflexive Compendium. Contemporary Problems of Social Work, 4(16), 84-86.

Miranda, M., Tadros, E. \& Molla, E. (2020). The Experience of Foster Care and Long-Term Attachment. American Journal of Family Therapy, 48(1), 87-106.

Orphanhood in the regions of Russia. (2018). Estimating the extent of the problem based on available statistics. Prepared by: Research Department of the Need Help Charity Foundation, Moscow. URL: https://nuzhnapomosh.ru/research/2018/sirotstvo-vregionakh-rf/ (accessed 17.10.2019).

Palibina, A.S. (2018). Social work on the prevention of social orphanage in the region (on the example of the Republic of Mordovia). Protection of Childhood: Problems, Searches, Solutions. The collection of materials of the All-Russian Scientific and Practical Conference dedicated to the Decade of Childhood in Russia. Ed. M.V. Smagina, pp. 579-583.

Rating agency "RIA Rating” of the media group MIA “Russia Today”. (2019). Rating of the quality of life of the population in the Russian regions. URL: https://riarating.ru/regions/20180214/630082372.html (accessed 22.09.2019).

Rating of the socio-economic situation of the regions. (2018). URL: http://riarating.ru/infografika/20180523/630091878.html accessed 13.10.2019).

Regions of Russia. (2017). Socio-economic indicators. Statistical collection. Moscow: Rosstat. Reznichenko, S. M., Takhumova, O. V., Zaitseva, N. A., Larionova, A. A., Dashkova, E. V., Zotikova, O. N. \& Filatov, V. V. (2018). Methodological aspects of assessing factors 
affecting the sustainable development of the region. Modern Journal of Language Teaching Methods, 8(11), 69-79.

Roche, S. (2019). A scoping review of children's experiences of residential care settings in the global South. Children and youth services review, 105, 124-130.

Summary reports on the form of federal statistical observation No. 103-RIK 2018 for Russia and the subjects of the Russian Federation. (2019). URL: https://docs.edu.gov.ru/document/b7b4176c2b3349c8370ec1f393aa2071/ (accessed 20.10.2019).

Sushko, V.A. (2017). Social orphanhood in modern Russia. Sociology, 4, 55-63.

The analysis scheme of the state of protection of children's rights in the region. (2019). URL: https// deti.khv.ru/images/skhema_analiza_regiona_2018.pdf (accessed 10.09.2019).

Tazik, A., Tazik, F., Tazik, A., \& Susaraie, A. H. (2019). Evaluation of the Relationship between Macroeconomic Variables and Industrial Price Index In Tehran Stock Exchange. Journal of management and accounting studies, 7(02), 31-38.

Vasilieva, E. Y. \& Frolova, E. V. (2019). The Provision of Housing for Children-orphans and Children Left Without Parental Care: Key Issues and Regional Practices. Social Policy and Sociology, 3(132), 101-110.

Zaitseva, N. A., Larionova, A. A., Filatov, V. V., Rodina, E. E., Zhenzhebir, V. N., Povorina, E. V. \& Palastina, I. P. (2018). Natural-Resource Potential Management of Region's Territorial Ecosystems. Ekoloji, 106, 495-502. 